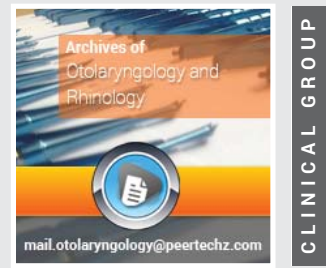

\section{Navarrete ${ }^{1 *}$, ML Torrent ${ }^{2}$, D Issa ${ }^{2}$ and J Salazar ${ }^{1}$}

'Chief of Otoneurology and Facial Palsy, Otorhinolaryngology Head and Neck Surgery, Autònoma University of Barcelona, Spain

${ }^{2}$ Rehabilitation Department, Facial Palsy Unity, Vall d'Hebron Hospital, Autònoma University of Barcelona, Spain

Received: 06 August, 2019

Accepted: 10 September, 2019

Published: 11 September, 2019

*Corresponding author: ML Navarrete, MD, PhD, Chief of Otoneurology and Facial Palsy, Otorhinolaryngology Head and Neck Surgery, Autònoma University of Barcelona, Spain, Tel: +34-934893000; Fax: +34-934894438; E-mail:mlna@telefonica.net

Keywords: Facial palsy; Seguelae; Myofascial treatment; Dry needling

https://www.peertechz.com

Check for updates

\section{Research Article}

\section{The use of myofascial techniques (dry needle) for the treatment of maintained muscule contraction in peripheral facial palsy sequelae}

\section{Abstract}

Introduction: Based on the clinical and neurophysiologic similarities between the myofascial pain and the facial palsy's maintained muscle contraction, we considered treating the latter with dry needling the trigger points found in the physical examination.

Objective: To assess the effect of dry needling as a method of treatment for the maintained muscle contraction, to improve pain and tightness as well as to facilitate movement.

Materials and Methods: We performed dry needling techniques to 5 random patients with facial palsy with maintained muscle contraction and trigger painful points noticed in physical exam. The dry needling technique was applied one or two months after botulinum toxin injection. After one week, the patient answered the Patient Global Impression of Improvement Scale and the Clinical Global Impression of Improvement Scale, through which relief of pain and tightness were assessed and the Likert scale to assess improvement in movement.

Results: The Patient Global Impression Improvement Scale results were "Much improved" in 4/5 patients and "Very much improved" in 1/5 patient. The Clinical Impression of Improvement Scale was "Improved" in all patients. The assessment of improvement in movement through the Likert Scale was of 5 in all cases.

Conclusions: Patients refer significant improvement in both pain and movement. We consider that the dry needling technique as a supplemental treatment after botulinum toxin may improve maintained muscle contraction and facilitate movement in the affected side of the face.

\section{Introduction}

The myofascial syndrome is a complex form of neuromuscular dysfunction with both motor and sensorial abnormalities, which imply the peripheral and central nervous systems. The myofascial pain is defined as the pain that originates from the muscle or muscle fascia and is associated with hypercontractility of the affected area and the presence of trigger points [1].

The postparalytic facial syndrome is defined as a conglomerate of clinical manifestations secondary to aberrant reinnervation of the facial nerve. It consists on the appearance of synkinetic movements, maintained muscle contractions of certain muscle groups, myokymia and postparalytic spasms of the affected side of the face, which interfere with the normal facial movements.
Maintained muscle contraction manifests as a muscular tension after aberrant regeneration of the nerve. If there is axonal damage, its regeneration will inevitably cause hyperactivity of the previously paralyzed muscles. Just as it occurs in the myofascial syndrome, during the physical exam of the patient with maintained muscle contraction (MMC) it is common to find painful trigger points within the muscle. The most common localizations are the procerus, the levator labii, the buccinators muscle, zygomaticus minor, depressor anguli oris, mentalis and zygomaticus major.

Based on the clinical similarities between the MMC in the facial palsy and the tense band found in the myofascial pain, and given that the neurophysiologic mechanisms for both entities are mediated through peripheral and central components, we pose the treatment of the MMC with dry needling of the trigger 
points. With such treatment the hope is to improve the pain and the hypercontractility without causing functional alterations.

In this manuscript, the use of a mechanical stimulus from a needle used as a physical agent to treat the myofascial pain syndrome after a severe facial palsy is explained. The term dry needling is used [1-3], to distinguish it from other invasive techniques that include infiltration of substances ranging from anesthesia, NSAIDs or botulinum toxin [4]. It has proven to be a very efficient way of treating the myofascial trigger points, especially when combined with physiotherapy treatment which helps enhance its effect $[1,5,6]$.

The dry needle technique consists on introducing monopolar needles coated with teflon in the myofascial trigger point (MTP), $1 \mathrm{~cm}$ deep [7,8]. These needles have the advantage of being thicker than the acupuncture ones, enhancing their capacity, and the coating facilitates the glide through the skin diminishing pain. Thanks to this technique, patients with MMC secondary to peripheral facial palsy from any etiology can be treated. Initially, weekly sessions are performed, and these are spaced in time, depending on the results obtained.

\section{Materials and Methods}

We randomly chose five patients from our daily clinical practice: 4 women and 1 man, with ages ranging from 40-51 years old. Time since facial palsy varied from 1-17 years, and one of the cases was a bilateral facial palsy. All patients had been treated with neuromuscular training and botulinum toxin (BT). Dry needle sessions were held 1 or 2 months after the BT.

During the patient's visit and after signing the informed consent, a Facial Grading System and a physical examination looking for MMC and trigger points, were done. Once the affected areas were recognized, antiseptic measures were implemented and the dry needle was inserted (Figure 1). Screw in and out myofascial technique is practiced, and the appearance of the local twitch response with the sympathetic response is obtained. This is repeated two or three times in a 10-15 minute-period.

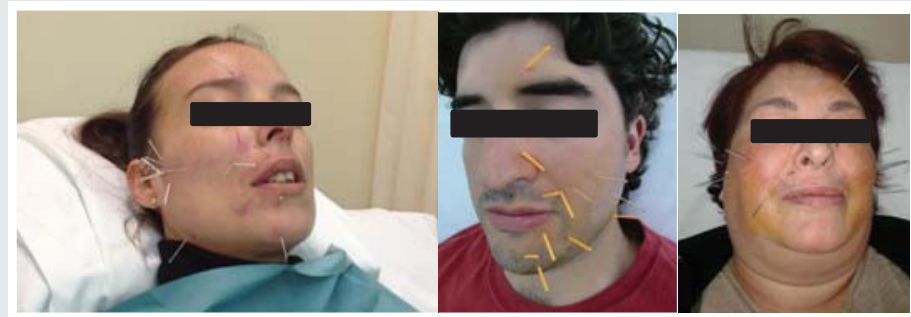

Figure 1: Patients treated by puncture dry with needle of acupuncture with guide on the trigger or the muscle band.

One week after treatment, both patient and/or doctor respond the following questionnaires:

Table 1. Patient Global Impression of Improvement Scale: a number is chosen to best describe the improvement in pain/ contracture after the needling treatment.
Table 1: Check the number that best describes the improvement in pain/contracture after the needling treatment by the Patient Global Impression of Improve Scale results were.

\begin{tabular}{|c|c|c|c|c|c|c|}
\hline & Score & patient 1 & patient 2 & patient 3 & patient 4 & patient 5 \\
\hline $\begin{array}{c}\text { Very much } \\
\text { better }\end{array}$ & 1 & & & $X$ & & \\
\hline Much better & 2 & $\mathrm{X}$ & $\mathrm{X}$ & & $\mathrm{X}$ & $\mathrm{X}$ \\
\hline A little better & 3 & & & & & \\
\hline No change & 4 & & & & \\
\hline Little worse & 5 & & & & \\
\hline $\begin{array}{c}\text { Much worse } \\
\text { Very much } \\
\text { worse }\end{array}$ & 6 & & & & \\
\hline
\end{tabular}

Table 2. Clinical Global Impression of Improvement Scale: the doctor chooses a number to best describe the improvement in the patient's contracture after the dry needling sesión.

Table 2: Check the number that best describes the improvement in contracture after the needling treatment by the Clinical Global Impression of Improvement Scale results were.

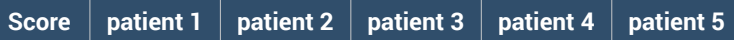

\begin{tabular}{|c|c|c|c|c|c|c|}
\hline Much better & 1 & & & & & \\
\hline Better & 2 & $x$ & $x$ & $x$ & $x$ & $x$ \\
\hline No change & 3 & & & & & \\
\hline Little worse & 4 & & & & & \\
\hline Much worse & 5 & & & & & \\
\hline
\end{tabular}

Table 3. Likert Test: is a basic question: Do you consider it is easier to move your face after the treatment?

Table 3: Do you consider it is easier to move your face after the treatment?

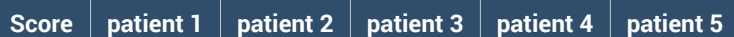

\begin{tabular}{|c|c|c|c|c|c|c|}
\hline Much better & 1 & & & & & \\
\hline Better & 2 & $x$ & $x$ & $x$ & $x$ & $x$ \\
\hline No change & 3 & & & & & \\
\hline Little worse & 4 & & & & & \\
\hline Much worse & 5 & & & & & \\
\hline
\end{tabular}

\section{Results}

Given that this is a preliminary project, we want to take the opportunity to present the use of the dry needling approach for treating the MMC in the patient with facial palsy.

Evidently, the small sample size does not allow for statistical data, and this being an observational study.

\section{Patients' and doctors' evaluations were as follow:}

According to the Patient Global Impression of Improve Scale (Table 1) results were: 4 patients responded 2 (better) and one patient selected option 1 (much better).

In the Clinical Global Impression of Improvement Scale (Table 2) results were 2 (better) for all patients. 
The Likert test (Table 3) resulted in an improvement in mobility with option 2 (better) for all patients.

A decrease in volume of the affected and treated MMC area was observed but not quantified.

Duration of effects varies amongst patients, depending on clinical situation of each one, ranging from a few weeks to a couple of months.

\section{Discussion}

Myofascial syndrome can be defined as the pain originating from the muscle or in the muscle fascia. It is an inflammatory process that comes along with pain and rigidity. As mentioned before, trigger points are pathognomonic, and they can be described as muscle indurations that are painful under pressure [1], causing pain, rigidity and lack of movement.

The postparalytic facial pain syndrome with MMCs has probably multiple physiopathologic mechanisms, including abnormal axonal ramifications after its regeneration, and an enhanced excitability in the facial motor neurons and the interneurons from the brainstem that mediate the trigeminofacial reflex.

Treatment with local injections of botulinum toxin has proven to be useful in diminishing the intensity of the synkinesis and the MMC, favoring a window period to optimize physiotherapy treatment. Nonetheless, there are certain muscle groups that are difficult to reach without causing functional damage to the affected side. These are the muscles in the malar zone, nasolabial groove, depressor labii inferioris, and orbicular oris, which are all implied in the oral-perioral movements.

The dry needling technique consists in introducing monopolar needles coated with teflon in the myofascial trigger point. Even though more studies are needed to confirm its efficacy, the fact that it is nearly unaggressive and has no complications whatsoever, make it a technique to take into account when evaluating and treating postparalytic faces [7].

The contraindications for dry needling are a few, and mostly relative: kids, coagulation problems and immunosuppression. Complications are barely documented but post puncture pain, muscle spasm and contact dermatitis could be a few $[9,10]$.

The technique is known as dry needling because no substance is administered. The effect of the needle in the trigger point is purely mechanic. The pain is diminished, the tone relaxes and the functionality of the muscle is restored, on occasions, immediately. Never the less, ongoing investigations are working toward clearing its effects, especially physiologically, because it is believed that it is capable of stopping the process that activates and perpetuates the myofascial trigger points.
As mentioned above, our results are preliminary. Improvement is translated into less rigidity of the affected side of the face and less interference of the MMC with the facial movements, improving pain and achieving less distorted facial movements. This more relaxed MMC helps patients in the neuromuscular retraining, as a better motor control is obtained.

\section{Conclusions}

1. Based on the clinical similarities between the MMC of the facial palsy and the tense band observed in the myofascial pain, we propose treating the MMC with dry needling of the trigger points found in the clinical exam. The goal is to improve pain due to hypercontractility and facilitate movement of the hemifacial muscles, with no risk of provoking functional losses.

2. Subjectively, a decrease in volume of the treated area has been documented, noted both by the patient and the physician.

3. This therapy can be a coadjuvant treatment to botulinum toxin injections, with the aim of improving hypercontractility and favoring facial movements in the affected side.

\section{References}

1. Simons DG, Travell JG, Simons LS (2002) Dolor y disfunción myofascial. El manual de los puntos gatillo. Volumen 1, Mitad superior del cuerpo. 2a ed. Madrid: Editorial Médica Panamericana. Link: http://bit.ly/2m9khYN

2. Dommerholt J (2004) Dry Needling in Orthopaedic Physical Therapy Practice Orthop Practice 16:11-16.

3. Borg-Stein J, Stein J (1996) Trigger points and tender points: One and the same? Does injection treatment help? Rheum Dis Clinics North Am 22: 305322. Link: http://bit.ly/2kEeTwb

4. Vecchiet L, Giamberardino MA, Saggini R (1991) Myofascial pain syndromes: clinical and pathophysiological aspects. Clin J Pain 7: S16-S22. Link: http://bit.ly/2k40elG

5. Dommerholt J (2001) Muscle pain syndromes. En: Cantu RI, Grodin AJ, editors Myofascial manipulation. Theory and clinical application. 2nd ed Gaithersburg: Aspen Publishers Inc 93-140.

6. Edwards J, Knowles N (2003) Superficial dry needling and active stretching in the treatment of myofascial pain. A randomized controlled trial. Acupunct Med 21: 80-86. Link: http://bit.ly/2l01QbJ

7. Ceccherelli F, Rigoni MT, Gagliardi G, Ruzzante L (2002) Comparison of superficial and deep acupuncture in the treatment of lumbar myofascial pain: a double-blind randomized controlled study. Clin J Pain 18: 149-153. Link: http://bit.ly/2kcnhmD

8. Karakurum B, Karaalin O, Coskun O, Dora B, Ucler S, et al. (2001) The dry needle technique: intramuscular stimulation in tension- type headache. Cephalalgia 21: 13-17. Link: http://bit.ly/2m9IM9n

9. Hong CZ (2002) New trends in myofascial pain syndrome. Zhonghua Yi Xue Za Zhi (Taipei) 65: 501-512. Link: http://bit.ly/2m6NG5L

10. Rachlin ES, Rachlin SR (2002) Myofascial pain and fibromyalgia. Trigge Point Management. 2nd ed. St Louis: Mosby, Inc Link: http://bit.ly/2IFvdx9

Copyright: (c) 2019 Navarrete ML, et al. This is an open-access article distributed under the terms of the Creative Commons Attribution License, which permits unrestricted use, distribution, and reproduction in any medium, provided the original author and source are credited. 